\title{
BRITISH STANDARDS FOR SPECTACLES
}

EARLIER articles have reviewed parts of the work of the British Standards Institution in the field of standardization of spectacles (Brit. J. Ophthal., $1956,40,611 ; 1959,43,509)$, but the publication of B.S. 3521, completing the series of Standards relating to spectacles, provides the opportunity for a general survey.

The nine British Standards fall into two categories with some overlap. There are, first, those of direct appeal to prescribers, 2738, 3162, 3199, and 3521 . These provide the criteria by which to judge the finished product, or state the language which discussion should use, or define the accuracy of the testing upon which prescribing is based.

The rest are primarily the manufacturers' concern, relating as they do particularly to the quality of materials and components. These are B.S. $3062,3172,3186,3352$, and 3462 and need not be studied except by those specially interested.

\section{B.S. 2738.}

This standard defines the permitted limits of departure from the prescription. It deals with tolerances on power, orientation and centration of lenses, it refers to quality both of material and finish, and it touches upon lenses taken as a pair. National Health Service dispensing is under contract to conform to the British Standard. It can hardly be fully understood without reference to

\section{B.S. 3199 .}

This standard defines a system, amplified from the datum system, for measurement of frames and provides a glossary. Such a system is fundamental to centration of lenses.

\section{B.S. 3162 .}

The precision of a measurement turns upon the tools available. This standard defines the accuracy of the lenses in a trial case, the "tools available", and hence the precision of a refraction. It provides also for a future tightening of the tolerances.

\section{Footnote}

The following British Standards relating to spectacles have been published:

B.S. 2738, "Spectacle Lenses".

B.S. 3062, "Spectacle Lens Materials".

B.S. 3162, "Ophthalmic Trial Case Lenses".

B.S. 3172, "Screw Threads of Unified Form for Spectacle Frames".

B.S. 3186, "Cellulose Acetate Sheet".

B.S. 3199, "Measurement of Spectacle Frames. Method and Glossary".

B.S. 3352, "Spectacle Frames made of Cellulose Acetate".

B.S. 3462, "Metal Spectacle Frames".

B.S. 3521, "Glossary of Ophthalmic Lenses".

They are obtainable from the British Standards Institution, 2 Park Street, London, W.1. 
B.S. 3521 .

In this standard are defined as many terms as were thought to be necessary to provide a complete vocabulary. At present there is a little overlap between this and the glossary in B.S. 3199, but a synthesis will probably take place later. Contact lens practitioners will find something of interest in B.S. 3521 in which, inter alia, the geometry of contact lenses is put, it is thought for the first time, into systematic form. This British Standard is more than a dictionary, for it aims at eliminating unsatisfactory terms and thereby, together with some new-coined terms and rigid definitions, at a precision of thought which can only be of benefit to all.

A matter of crucial interest to prescribers is dealt with in Appendix A of B.S. 3521. Here are set out the recommended methods of writing prescriptions and, because they may seem tedious, some further explanation is justified.

The recommended method is based upon the need to avoid doubt, whether the prescription is in manuscript or typescript. The $0^{\circ}-360^{\circ}$ protractor is essential for the simplest unique specification of a field limit or the base setting of a prism. It also defines a decentration without ambiguity. It seemed logical to bring the orientation of an astigmatic element into the same system, and this needs only the use of the UPPER semicircle for $0^{\circ}-180^{\circ}$, instead of the lower to which our trial frames have accustomed us. This is already the international system "Axint", which itself accords with "Campint", the notation for fields (Brit. J. Ophthal., 1951, 35, 496).

In this country, Axint has not yet found much acceptance. Campint, in which the field of vision is imagined drawn upon a transparent screen between patient and observer, has made less progress. With the recognition in this corpus of British Standards of the $0^{\circ}-360^{\circ}$ protractor, one system for specifying uniquely all angular directions, whether for cylinders, prisms, decentrations, or field limits, is established, and much advantage would be gained if every ophthalmologist made a determined effort to adopt it personally.

Taken together, these nine British Standards represent a notable advance in precision in a branch of medicine (and its allied technology) which is pre-eminently characterized by fine detail and by accuracy.

Nigel Cridland. 